\title{
A Soft Tissue Myxoma on the Palate: A Case Report
}

\author{
Ji-Woo Ha' ${ }^{1}$, Won Jung ${ }^{2}$, Kyung-Eun Lee ${ }^{2}$, Bong-Jik Suh ${ }^{2}$ \\ ${ }^{1}$ Department of Oral Medicine, School of Dentistry, Jeonbuk National University, Jeonju, Korea \\ ${ }^{2}$ Department of Oral Medicine, Institute of Oral Bioscience, School of Dentistry, Jeonbuk National University, Jeonju, Korea
}

Received August 19, 2020

Revised September 10, 2020

Accepted September 10, 2020

Correspondence to:

Won Jung

Department of Oral Medicine, School of Dentistry, Jeonbuk National University, 567

Baekje-daero, Deokjin-gu, Jeonju 54896,

Korea

Tel: +82-63-250-2060

Fax: +82-63-250-2058

E-mail: jungwon@jbnu.ac.kr

https://orcid.org/0000-0002-8728-8013
Myxomas in the orofacial regions are relatively uncommon tumors that occur in two different types: odontogenic myxomas and soft tissue myxomas. Odontogenic myxomas, derived from the mesenchymal cells such as papillae, dental follicles, or periodontal ligament, occur commonly in the maxilla and mandible. However, soft tissue myxomas in the oral cavity are rare and have been previously reported in only about 30 cases of unknown pathogenesis. The aim of this case report is to present a new case of oral soft tissue myxoma in a 37-year-old male patient who presented with a soft, exophytic round mass on the palate.

Key Words: Myxoma; Palate; Soft tissue myxoma

\section{INTRODUCTION}

Myxoma is a true neoplasm, which resembles primitive mesenchyme. It consists of stellate cells in a loose mucoid stroma through which delicate reticulin fibers course, in irregular directions [1]. Currently, myxoma is considered rare, locally infiltrative benign tumor of the connective tissue, which does not metastasize [2]. The tumors show different growth rates. However, there are usually long periods of inactivity, which may precede or follow periods of short and rapid growth [1]. If inadequate resection has been performed, it may be capable of local destruction and can even be fatal in rare circumstances [1,2]. It can affect persons of all ages although it is not common in children or young adolescents [3].

Myxomas are mainly reported in the heart, and comprise nearly half of the benign tumors of the heart. Although cardiac myxomas occur in all age groups, they are frequent between the third and sixth decades in particular [4]. Other types of myxomas arise in the somatic soft tissue, which is named as soft tissue myxoma, mainly discovered in the skeletal muscles, dermal and subcutaneous tissue, pelviperineal tissue, and proximal to a large joint. Myxomas in the bones can almost be considered as the tumors of the facial skeleton, because the lesions rarely exist in the extra-gnathic bones [2].

Within the head and neck, they were most frequently found in the mandible or the maxilla and are often known as odontogenic myxomas [2,5]. Soft tissue myxomas were identified in the skeletal muscles, subcutaneous tissues, and fascial planes. Odontogenic myxomas arise more frequently than soft tissue myxomas in both adult and pediatric patient populations [2].

Epivatianos et al. [3] suggested that soft tissue myxoma occurred infrequently in the oral cavity, reporting only 24 cases in their review of literature. The objective of this case report is to present a new case of soft tissue myxoma arising in the palate of a 37-year-old male patient.

Copyright (c) 2020 Korean Academy of Orofacial Pain and Oral Medicine. All rights reserved.

(c) This is an open-access article distributed under the terms of the Creative Commons Attribution Non-Commercial License (http://creativecommons.org/licenses/by-nc/4.0/), which permits unrestricted non-commercial use, distribution, and reproduction in any medium, provided the original work is properly cited. 


\section{CASE REPORT}

A 37-year-old male was referred to the department of oral medicine at the Jeonbuk National University Hospital from a local dental clinic in January 2020. He complained of an asymptomatic mass that had appeared in the palate about 2 months previously.

Clinical examination showed a soft, exophytic round mass located in the hard palate, measuring about $7 \mathrm{~mm}$ in diameter (Fig. 1). The lesion was covered by normal mucosa, and not tender to palpation. The patient's medical and dental histories were unremarkable. Under local anesthesia, a surgical removal was carried out. The excised specimen was sent for histopathological evaluation.

Microscopically, the tumor was composed of loosely arranged stellate and spindle shaped cells with ambiguous

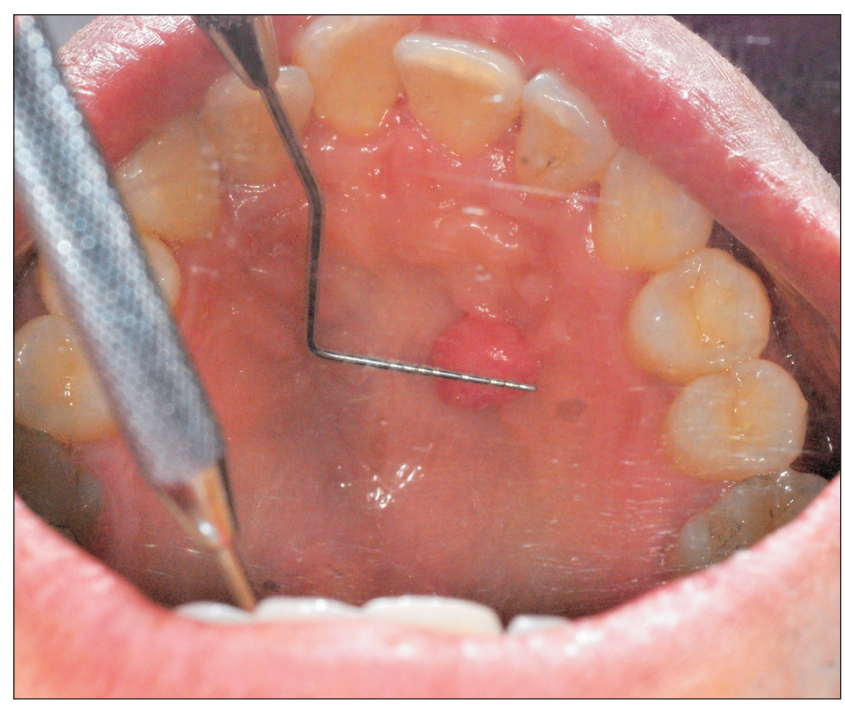

Fig. 1. Clinical examination revealing the presence of a soft and round mass measuring about $7 \mathrm{~mm}$ in diameter on the right palate. myxoid stroma identified through Hematoxylin and eosin staining (H\&E staining) (Fig. 2). Additional examinations had been performed for differential diagnosis as H\&E staining examination had limitations in the final diagnosis. Stromal substance was stained with Alcian blue at $\mathrm{pH}$ 1.0 and pH 2.5 (Fig. 3). Reticulin stain showed the presence of fine reticulin fibers in the mucinous substance (Fig. 4). Immunohistochemical stains with vimentin were positive, while those with S-100 protein were negative. The lesion was negatively stained for desmin and smooth muscle actin and CD34 were positive in blood capillaries (Fig. 5).

The final diagnosis of soft tissue myxoma was made based on the histopathological findings. After six months of the operation there had been no recurrence of the lesion.

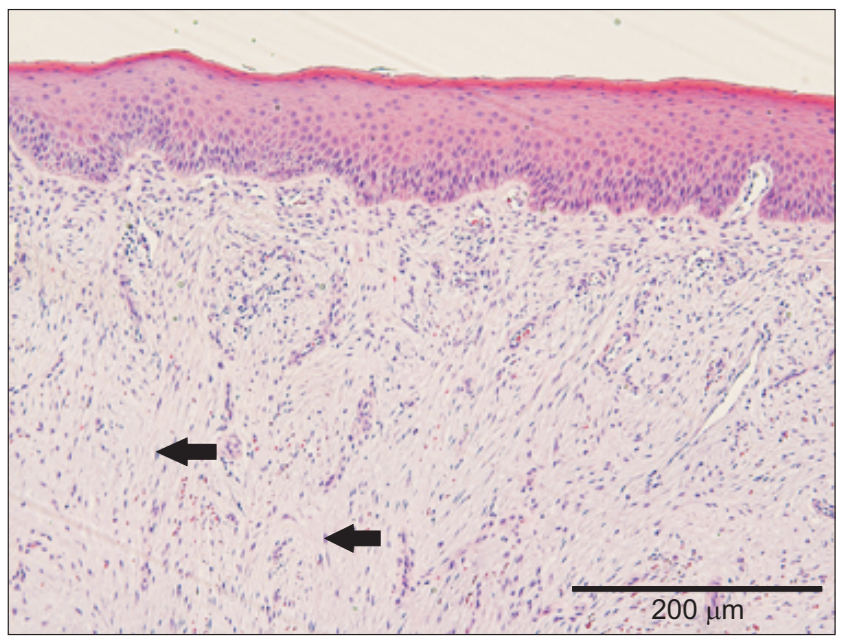

Fig. 2. Histological examination showing that the lesion was composed of loosely arranged hypocellular lesion composed of stellate and spindle shaped cells (arrows) (H\&E staining; Magnification, $\times 100)$.
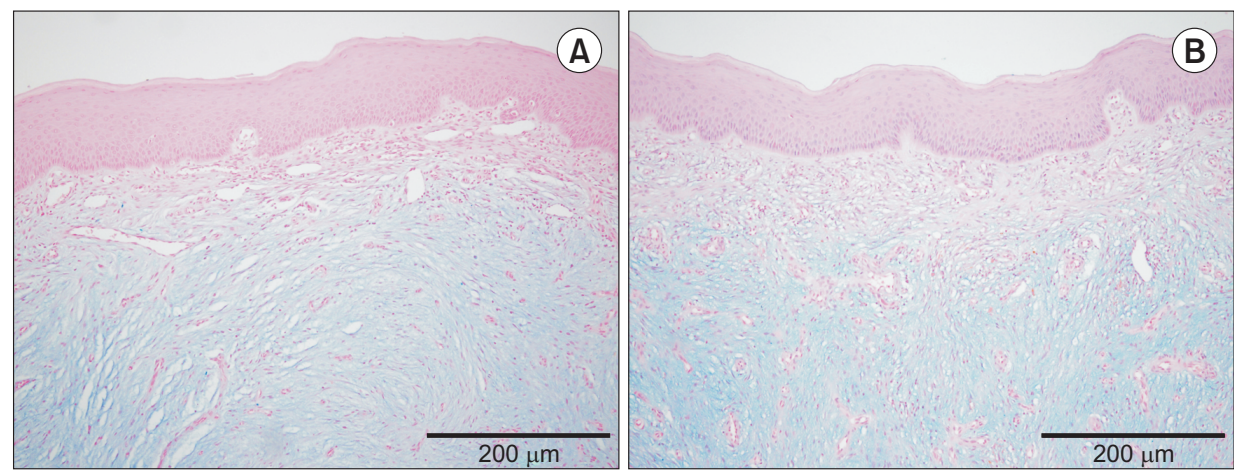

Fig. 3. Alcian blue staining (ABS) revealing abundant myxoid materials in the stroma. (A) ABS showing positive in $\mathrm{pH} 1.0$ (Magnification, $\times 100$ ) and (B) showing stronger positive reaction at $\mathrm{pH} 2.5$ indicating abundant hyaluronic acid in stroma (Magnification, $\times 100$ ). 


\section{DISCUSSION}

In the orofacial regions, myxomas occur in two different types, odontogenic myxomas and soft tissue myxomas. Odontogenic myxomas are benign tumors derived from mesenchymal cells such as papillae, dental follicles, or periodontal ligament, occurring more commonly than soft tissue myxomas in the maxilla and mandible [6]. Myxomas of

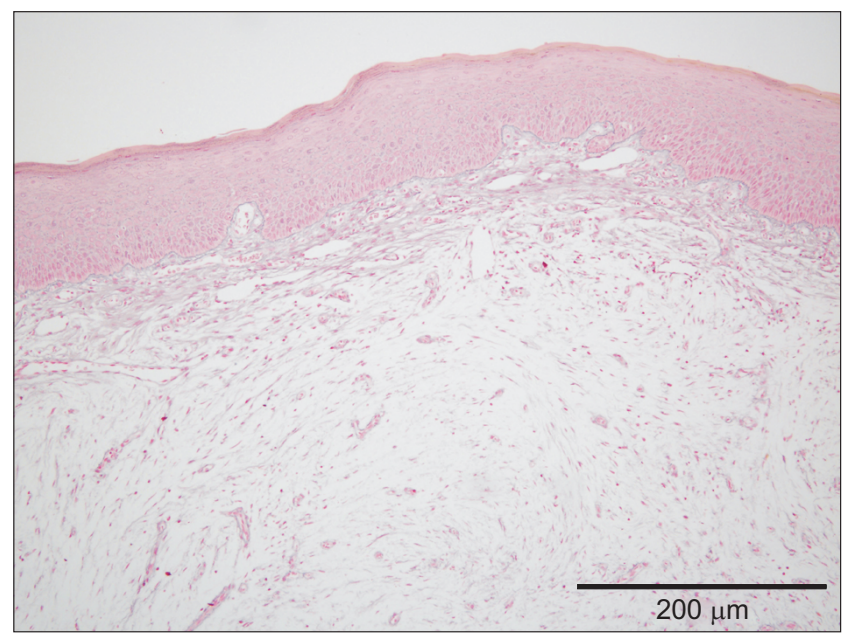

Fig. 4. Reticulin stain showing the presence of fine reticulin fibers (Magnification, $\times 100$ ). the jaws grow slowly with a tendency of expanding, thinning of the cortex, and sometimes lasting for several years $[2,6]$. They are likely to loosen and lead to displacement of the teeth if the tumor exists in the tooth-bearing area. Radiographic findings of the tumors often appear as wellcircumscribed, radiolucent areas, which may include a fine, soap-bubble trabeculated appearance [2]. Peripheral odontogenic myxomas, which are considered the counterpart of odontogenic myxomas, usually present as exophytic gingival mass with no pain in the soft tissue overlying the tooth supporting structures or in the extra-bone in the jaw $[6,7]$.

Soft tissue myxomas have been reported in the skeletal muscles, subcutaneous tissues, and fascial plane in the maxillofacial regions [2]. Although there are several theories about the pathogenesis of the soft tissue myxomas, the prominent hypothesis is that an altered fibroblast could produce an excess of mucopolysaccharides. They were commonly considered to be incapable of forming mature collagen even if some cells could retain this capacity. However, further studies are necessary to clarify the origin of the myxomas, as the histogenesis of the tumor remains obscure [8].

The clinical characteristics of soft tissue myxomas reported in the oral cavity are not pathognomonic. They show a
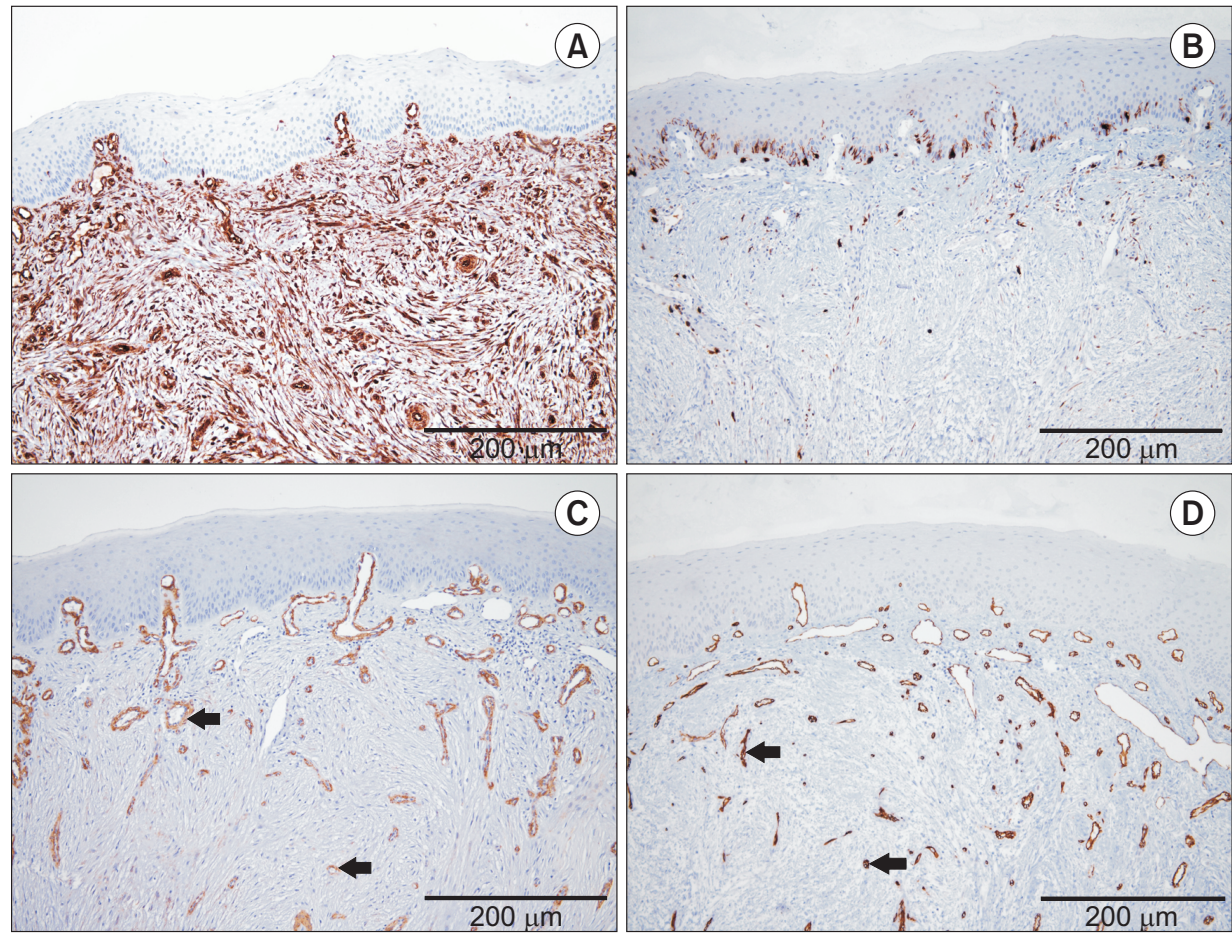

Fig. 5. (A) Immunohistochemical (IHC) stain for vimentin showing a strong positive reaction with connective tissues including the lesion, which means the lesion originated from the mesenchymal cells (Magnification, $x$ 100). (B) IHC stain for $S-100$ protein showing a negative reaction in the lesion (Magnification, $\times 100$ ). (C) IHC stain for smooth muscle actin showing a negative reaction except in the smooth muscles of the blood capillaries (arrows) (Magnification, $\times 100$ ). (D) IHC stain for CD34 showing a negative reaction except in the blood capillaries (arrows) (Magnification, $\times 100$ ). 
slight female predilection and the age of affected patients ranges from 2-weeks to 74-years with the largest number of cases in the fourth decades. The most common complaint was a slowly growing painless tumor with a duration of range from 1 month to 24 years $[3,8]$. Clinically, most of the previously reported cases were misdiagnosed as fibroma, lipoma, fibroepithelial polyp, oral focal mucinosis and tumor of a minor salivary gland [9]. Definitive diagnosis can be established only after histopathological analysis of the lesion [3].

Epivatianos et al. [3] reported that the most frequent regions of the tumors was the palate (11 cases), followed by the buccal mucosa ( 5 cases), the lips ( 3 cases), and the floor of the mouth (2 cases). Recently, Nisi et al. [10] reported additional cases of soft tissue myxomas. In this review, 3 more cases of the buccal mucosa and lips, respectively, were identified. To summarize, to the best of our knowledge the most frequent intraoral region where the soft tissue myxomas occurred is the palate (14 cases), followed by the buccal mucosa (8 cases).

Histologically, soft tissue myxomas in H\&E staining are hypocellular lesion composed of spindle and stellate cells embedded in abundant myxoid or mucous stroma that contains reticulin fibers [3]. Myxoid or mucous stroma of soft tissue is composed of plentiful hyaluronic acid [1], which is non-sulfated glycosaminoglycans (GAG), and sulfated GAG such as chondroitin sulfate [11]. A ratio of hyaluronic acid to chondroitin sulfate is $4: 1$ [12]. However, non-sulfated GAG might be difficult to be seen in H\&E staining. Alcian blue staining (ABS) should be performed for differential diagnosis. $\mathrm{ABS}$ (pH 1.0) demonstrates sulfated GAG and ABS (pH 2.5) shows alcinophilia in the tissues which contain hyaluronic acid or sialomucin [13]. In our case, ABS revealed positive in $\mathrm{pH} 1.0$ and stronger positive reaction at $\mathrm{pH}$ 2.5. The stroma in this lesion is composed of mainly non-sulfated GAG with some sulfated GAG. Additionally, immunohistochemical stain for reticulin fibers is supposed for final diagnosis, because perception of reticulin fiber with $\mathrm{H} \& \mathrm{E}$ staining is not possible [8].

The differential diagnosis of soft tissue myxomas from other myxomatous tumors can be extremely challenging because the significant histological features observed through a light microscope overlap among the different entities [14]. Particularly, the following differential diagnosis for myxoid-like lesions should be considered: myxomatous degeneration in a fibrous lesion, oral focal mucinosis and nerve sheath myxomas $[9,13]$. The lesions are occasionally misdiagnosed as malignant [15], and inversely, other myxoid malignant tumors such as myxoid liposarcoma and myxofibrosarcoma could be confused with soft tissue myxomas [11]. Therefore, definitive histological diagnosis should deliberatively be made. Integration of histopathological examination with comprehensive clinical and radiographic analysis is essential. Additionally, evaluation of the immunohistochemical expression of biomarkers in the lesion may provide an improved overall understanding of the origin, behavior, appropriate treatment and prognosis of myxomatous tumors [14].

The first oral focal mucinosis is considered the counterpart of cutaneous focal mucinosis occurring in the oral cavity. Histologically, the lesion shows a localized area characterized by accumulations of hyaluronic acid surrounded by relatively dense fibrous connective tissues [16]. The differential diagnosis should be based on the criteria established by Tomich. Oral focal mucinosis can be distinguished from myxomas by the lack of reticulin fibers in the myxoid stroma which is clearly localized from the surrounding tissues [17]. In our case, reticulin stain showed the presence of reticulin fibers and the lesion was not clearly defined from the surrounding fibrous connective tissues. Nerve sheath myxoma is a benign tumor thought to develop from perineural cells or peripheral nerves [9]. Histologically, it shows a well-circumscribed, but non-encapsulated myxomatous lesion, arranged in several lobules by connective tissue septa [18]. The majority of cells are spindle-shaped with a fascicular sequence, and are strongly positive for S-100 protein which confirms their neural origin $[3,16]$. This diagnosis was excluded in our case because there were no septa or lobule structures in the microscopic image and the result of immunohistochemical stain with S-100 protein was negative. Next are the fibrous tumors with myxomatous degeneration, which were commonly observed as overgrowth lesions [19]. They can be excluded by the presence of mast cells and inflammatory cell infiltrations in the myxomatous areas. Histologic differential diagnosis should include other origin types of neoplasms with extensive areas of 
myxomatous degeneration [19]. Special staining techniques and immunohistochemical analysis are helpful in identifying and differentiating these lesions. Differentiated elements, such as chondroblasts, rhabdomyoblasts, or lipoblasts make the diagnosis of myxomas impossible. Instead, it would indicate the myxomatous degeneration of a particular tumor [2]. The mucoid matrix of myxomas is stained strongly with Alcian blue and mucicarmine, as well as periodic acid-Schiff, although it is not specific. Similarly, in our case, immunohistochemical staining reveals that myxoma stains positive for vimentin, but negative for desmin and S-100. Staining for cytokeratin also shows a negative reaction [20].

The first choice in the treatment of soft tissue myxomas is surgical excision with adequate margins to prevent recurrences. It is assumed that the difficulty of tumor eradication is partially based on the poor definition of the tumor margins. Conservative treatment is indicated only in lesions close to vital structures, especially in young patients. Relapses of soft tissue myxomas range from 5\% to 30\%. They are associated with the anatomical location and treatment. Of the cases previously reported in literature, none of the soft tissue myxomas in the oral cavity had recurred [8].

In our case, the diagnosis of soft tissue myxoma was made based on histological and immunohistochemical findings. Because clinical features of soft tissue myxomas are not pathognomonic, a definitive diagnosis can be established after histological analysis of the lesion is performed. Even with histological examination, it may be difficult to differentiate myxomas from above-mentioned tumors showing myxoid stroma. Especially, the differential diagnosis of soft tissue myxoma between myxomatous degeneration of fibrous tumors or other origin types of neoplasm should be given careful consideration because of the potential risk of malignancy. Even though it is rarely found in the oral cavity, soft tissue myxomas should be considered a differential diagnosis of the benign tumor occurring in intraoral regions.

\section{CONFLICT OF INTEREST}

No potential conflict of interest relevant to this article was reported.

\section{ORCID}

\author{
Ji-Woo Ha \\ https://orcid.org/0000-0002-6708-796X \\ Won Jung \\ https://orcid.org/0000-0002-8728-8013 \\ Kyung Eun Lee \\ https://orcid.org/0000-0001-8923-1478 \\ Bong-Jik Suh \\ https://orcid.org/0000-0002-1817-4645
}

\section{REFERENCES}

1. Purdy Stout A. Myoxma, the tumor of primitive mesenchyme. Ann Surg 1948;127:706-719.

2. Andrews T, Kountakis SE, Maillard AA. Myxomas of the head and neck. Am J Otolaryngol 2000;21:184-189.

3. Epivatianos A, Iordanidis S, Zaraboukas T. Myxoma of the oral soft tissues: report of a case and literature review. J Oral Maxillofac Surg 2007;65:317-320.

4. Reynen K. Cardiac myxomas. N Engl J Med 1995;333:1610-1617.

5. Ghosh BC, Huvos AG, Gerold FP, Miller TR. Myxoma of the jaw bones. Cancer 1973;31:237-240.

6. Aytac-Yazicioglu D, Eren H, Görgün S. Peripheral odontogenic myxoma located on the maxillary gingiva: report of a case and review of the literature. Oral Maxillofac Surg 2008;12:167-171.

7. Mascitti M, Togni L, Pirani F, Rubini C, Santarelli A. Peripheral odontogenic myxoma: report of two new cases with a critical review of the literature. Open Dent J 2018;12:1079-1090.

8. Manjunath K, Jain MK, Jain A. Soft tissue myxoma of the cheek. Int J Stomatol Occlusion Med 2014;7:18-21.

9. James L, Shetty A, Jaypal N, Okade D, Kailasam S. Oral soft tissue myxoma. J Indian Acad Oral Med Radiol 2012;24:152-154.

10. Nisi M, Izzetti R, Gabriele M, Pucci A. Oral intramuscular myxoma: case report and brief review of the literature. Oral Surg Oral Med Oral Pathol Oral Radiol 2020. doi: 10.1016/ j.oooo.2020.03.053. [Epub ahead of print]

11. Allen PW. Myxoma is not a single entity: a review of the concept of myxoma. Ann Diagn Pathol 2000;4:99-123.

12. Slootweg PJ, van den Bos T, Straks W. Glycosaminoglycans in myxoma of the jaw: a biochemical study. J Oral Pathol 1985;14:299-306.

13. Hoshino M. The histochemistry of hyaluronic acid and related mucosaccharides in the cerebral and other arteries of the dog. Nagoya J Med Sci 1974;37:33-43.

14. Hamza SA, El-Azab SM, El-Ghani SFA. Odontogenic myxoma versus soft tissue myxoma: immunohistochemical study. Egypt Dent J 2016;62:233-238.

15. Ramaraj PN, Sah SP. Myxoma of oral soft tissue. J Nepal Med Assoc 2003;41:266-270.

16. Soda G, Baiocchini A, Bosco D, Nardoni S, Melis M. Oral focal 
mucinosis of the tongue. Pathol Oncol Res 1998;4:304-307.

17. Tomich CE. Oral focal mucinosis. A clinicopathologic and histochemical study of eight cases. Oral Surg Oral Med Oral Pathol 1974;38:714-724.

18. Prado JD, Andrade RG, Silva-Sousa YT, Andrade MF, Soares FA, Perez DE. Nerve sheath myxoma of the gingiva: report of a rare case and review of the literature. J Periodontol 2007;78:1639-
1643.

19. Rapidis AD, Triantafyllou AG. Myxoma of the oral soft tissues. J Oral Maxillofac Surg 1983;41:188-192.

20. Moore BA, Wine T, Burkey BB, Amedee RG, Butcher RB 2nd. Sphenoid sinus myxoma: case report and literature review. Ochsner J 2008;8:166-171. 